Published in final edited form as:

Pediatr Neurol. 2007 February ; 36(2): 73-80.

\title{
Hemorrhagic Stroke in Children
}

Lori C. Jordan M.D. and

Fellow, Cerebrovascular and Pediatric Neurology, Johns Hopkins University School of Medicine, 200 N. Wolfe St., Suite 2158, Baltimore, MD 21287, Email: ljordan2@jhmi.edu, Phone: 410-614-6054, Fax: 410-614-2297

Argye E. Hillis M.D.

Professor of Neurology, Johns Hopkins University School of Medicine, 600 N. Wolfe St., Phipps 126, Baltimore, MD 21287, Email: argye@jhmi.edu, Phone: 410-614-2381, Fax: 410-614-9807

\section{Abstract}

Hemorrhagic stroke accounts for approximately half of stroke in childhood. Unlike arterial ischemic stroke, there are no consensus guidelines to assist in the evaluation and treatment of these children. We review the literature on the evaluation, treatment, etiology and neurologic outcome of hemorrhagic stroke in children. Important differences between pediatric and adult hemorrhage are highlighted, as treatment guidelines for adults may not be applicable in all cases. Needed future research and potential therapies are also discussed.

\section{Introduction}

With an incidence of 2-3/100,000 children, stroke is among the top ten causes of death in childhood [1,2], and is as common as brain tumor in children [3]. A study of a California-wide hospital discharge database found an incidence rate of 1.1 per 100,000 person-years for hemorrhagic stroke and 1.2 per 100,000 person-years for ischemic stroke [4]. Thus, nearly half of pediatric strokes are hemorrhagic. Typically, the term "hemorrhagic stroke" (HS) includes spontaneous intraparenchymal hemorrhage (IPH) and non-traumatic subarachnoid hemorrhage (SAH) (Figure 1). Patients with traumatic IPH, primary subdural or epidural hematomas, or hemorrhagic transformation of ischemic stroke are usually not considered to have a hemorrhagic stroke [5,6]. For the purposes of this article, we will focus on IPH, the most common type of HS. Non-traumatic SAH is most often due to intracranial aneurysm and is evaluated and treated differently, though like IPH, recommendations for childhood SAH are based on the adult literature. Two recent pediatric intracranial aneurysm case series and reviews of the literature are available $[7,8]$.

Pooled data from retrospective cohort studies and case series suggest that overall mortality from HS is approximately $25 \%$ in children; significant disability is present in $42 \%$ of those who survive [6]. Despite the public health impact of childhood HS, there are no management or treatment guidelines $[4,6,9]$. In contrast, two consensus papers provide guidelines for the evaluation and treatment of arterial ischemic stroke in childhood, although clinical trials are still lacking [10,11]. Only one prospective cohort study of children with stroke included HS [12]. Additional literature consists primarily of case series and retrospective cohorts (Table 1); hence, there are limited data on risk factors, time to presentation, clinical-radiologic correlation,

Correspondence to: Lori C. Jordan M.D..

Publisher's Disclaimer: This is a PDF file of an unedited manuscript that has been accepted for publication. As a service to our customers we are providing this early version of the manuscript. The manuscript will undergo copyediting, typesetting, and review of the resulting proof before it is published in its final citable form. Please note that during the production process errors may be discovered which could affect the content, and all legal disclaimers that apply to the journal pertain. 
outcome and recurrence. There are no proven or widely accepted strategies for acute management or diagnostic evaluation of IPH in childhood, and limited data exist on the risks versus benefits of existing treatment approaches. Current practices are based on experience and extrapolation from the few adult IPH clinical trials. However, because IPH in adults is most commonly due to hypertension or amyloid angiopathy [13], the application of adult data in children is highly questionable. Unfortunately, clinicians treating children with IPH must extrapolate from the adult literature for diagnostic and treatment strategies [14].

\section{Methods}

A search of Medline and Embase (from 1966 to June 2006) was conducted with the following MESH search terms: "Cerebral hemorrhage AND child AND cerebrovascular accident." Additional non-mesh searches were conducted using search terms "hemorrhagic stroke, intracerebral hemorrhage, intraparenchymal hemorrhage, children, spontaneous." Searches were limited to humans. Additional articles were identified by reference review. Titles that suggested a paper about HS or IPH in children were pulled for abstract review. Inclusion and exclusion criteria were applied to abstracts. Inclusion criteria: studies published in English that included children with HS who were < age 20 at stroke onset and provided information on stroke etiology and outcome. Exclusion criteria: case series including less than 5 patients, articles that included children with primary subdural or epidural hemorrhages, articles where outcomes could not be determined for patients with HS. If uncertainty existed regarding these criteria, the paper was pulled for full-text review. Data from studies meeting these criteria were compiled in Tables 1 and 2.

\section{Results}

The prospective stroke registry in Dijon, France is the only prospective cohort study that met criteria [12]. No treatment trials were found. All remaining studies were retrospective cohorts, case control studies, and case series.

\section{Risk factors for HS in childhood}

Retrospective case series suggest that IPH in childhood is most often due to arteriovenous malformation, hematologic abnormality, or brain tumor (Table 2) [15-17]. Other etiologies include cavernous hemangioma [18], vasculopathy, vasculitis, cerebral and systemic infections, and rarely, illicit drug use.

Arteriovenous malformations (AVM) account for 14\% [19] to 46\% [12] of HS in children and nearly $50 \%$ of IPH [16]. Cavernous malformations are infrequently mentioned as an etiology for HS in childhood, probably because they are generally detected on MRI. Many studies listed in table 2 were completed before MRI was introduced in 1982 [20]. However, those that do report cavernous malformations indicate that these malformations may account for $20-25 \%$ of pediatric IPH $[9,12,21]$.

Hematologic abnormalities are reported to be the major risk factor in 10 to $30 \%$ of HS in most series $[5,12,15,22]$. Hematologic causes of IPH include thrombocytopenia and hemophilia, and coagulopathies. Coagulopathies may be related to liver failure, disseminated intravascular coagulation, or rarely may be iatrogenic; e.g. anticoagulation with heparin for cardiac surgery or extracorporeal membrane oxygenation (ECMO) [23]. Nevertheless, not all children with IPH have coagulation testing as part of their diagnostic evaluation. For example, four of 15 (27\%) children with sickle cell disease and IPH did not have routine coagulation studies such as a prothrombin time or partial thromboplastin time performed [24]. 
There are few data regarding the incidence of IPH in children with cancer. One case series indicated that brain tumors may account for as many as $13 \%$ of IPH in children [15]. The largest case series of children with both malignancy and brain hemorrhage $(n=51)$ included epidural and subdural hemorrhages as well as SAH and IPH e.g. intracranial rather than just intraparenchymal hemorrhage [25]. In this series from a tertiary children's cancer center, only $3 \%$ of 1036 children with brain tumor developed intracranial hemorrhage (ICH), and only $1 \%$ of 1597 children with acute leukemia developed ICH [25]. In 10 children who suffered hemorrhage directly into a primary or metastatic brain tumor, mortality related to the hemorrhage was $50 \%$.

\section{Special populations}

Brain hemorrhage is estimated to occur in 0.1 to $1.0 \%$ of children with idiopathic thrombocytopenia purpura (ITP) [26]. A review of the medical literature from 1954 to 1998 revealed 75 published cases of ICH in children with ITP [27]. In two children (3\%), ICH was the presenting feature of ITP. A total of seven children (10\%) had ICH within 3 days of diagnosis, and $72 \%$ had ICH within 6 months of diagnosis. Platelet counts were reported in 49 of 72 children. Platelet count was less than $10,000 / \mu 1$ in $71 \%$ of these children, 10,000 to $20,000 /$ $\mu \mathrm{l}$ in $27 \%$ and more than $20,000 / \mu \mathrm{l}$ in only one patient (2\%). Status of treatment for ITP was reported for 44 patients. Treatment with steroids, intravenous immunoglobulin (IVIG), splenectomy or some combination of these had been initiated in $70 \%$ of these patients prior to ICH. Mortality for children with ITP and ICH was 55\%.

Hemophilia also carries an increased risk of ICH. The prevalence of intracranial (epidural, subdural, and parenchymal) hemorrhage in hemophiliac children has been reported to be between $2.9 \%$ and $12 \%$ [28-30]. ICH is most common in young boys, with a median age at onset of 5.9 months to 2 years [28,29]. Trauma is the most important risk factor for ICH in children with hemophilia [28]; other risk factors include factor VIII or IX inhibitors, increased use of factor prophylaxis, and reduced annual household income [29]. Post-traumatic ICH in hemophilia can be indolent, with a symptom-free interval of up to 10 days [31].

Children with sickle cell disease (SCD) have a markedly increased risk of both hemorrhagic and ischemic stroke. The Baltimore-Washington Cooperative Young Stroke Study found an incidence of HS of 285 per 100,000 person-years in children with SCD, nearly a 250 -fold risk over unaffected children [32]. The Cooperative Study of Sickle Cell Disease found a more modest increase in HS incidence in children and young adults, ranging from 17 to 44 per 100,000 person-years [33]. In a recent study of 15 children with SCD and HS, factors associated with hemorrhage included pre-morbid hypertension, transfusion within the last 14 days, treatment with corticosteroids, and perhaps non-steroidal anti-inflammatory drugs [24]. Other risk factors identified in cohort studies and case series of SCD include: age, low steady-state hemoglobin concentration and high steady-state leukocyte count [33], as well as cerebral aneurysms, moyamoya, hypertension, acute chest syndrome, and overly aggressive transfusion [34-37]. Appropriate treatment after HS in SCD is unclear; however, patients with SAH and IPH with arterial occlusive disease are often placed on transfusion therapy as they are for ischemic stroke [38].

\section{Diagnostic challenges in childhood ICH}

The appropriate diagnostic evaluation in children with spontaneous IPH has not been established. Computed tomography (CT) is still considered to be the initial imaging study of choice by most authors, because it is rapid, widely available, and clearly distinguishes hemorrhagic and ischemic stroke [14]. Magnetic resonance imaging (MRI) sequences such as susceptibility-weighted images clearly identify hemorrhage, but are not universally available and require some experience and training to correctly identify the hemorrhage [39]. A recent 
study found that a combination of MRI, MRA and MRV images accurately identified the cause of IPH in 25 of 38 children (66\%) [40]. There were 2 false negative MRIs; one patient had a mycotic aneurysm, the other had a peripherally located AVM evident on conventional cerebral angiography (CCA). Interestingly, in the same study, CCA alone had a diagnostic yield of $61 \%$ that was statistically equivalent to the yield of the combination of MRI, MRA and MRV (40). In another series of children with non-traumatic IPH, the cause of bleeding was established in $97 \%$ of children who underwent CCA compared with $80 \%$ of children who did not have angiography [15]. However, fewer than 50\% of children with IPH undergo CCA [15,41]. Recent literature indicates that CCA in children can be relatively safe; in a series of 241 pediatric cerebral angiograms, the rate of major complications was only $0.4 \%$ [42].

Coagulation studies and other basic laboratory tests are recommended in the American Heart Association guidelines for management of intracerebral hemorrhage [14]. There is no evidence to suggest that an extensive evaluation for a bleeding diathesis is helpful, though no studies have been done in children with HS.

\section{Medical Management}

No medical management guidelines are available for pediatric patients with spontaneous IPH, but most guidelines for adults, from the American Heart Association [14], are applicable to children. Fluid management to maintain euvolemia and maintenance of body temperature at normal levels with acetaminophen and cooling blankets are recommended [14]. Temperature elevation, $>37.5^{\circ} \mathrm{C}$, has been shown to increase the likelihood of poor outcome in adults with IPH [43]. Careful monitoring for and treatment of hydrocephalus is essential. Perihematomal edema is also typical with IPH; in one study, absolute edema volume doubled in the first 24 hours after presentation [44]. Osmotherapy is recommended for elevated intracranial pressure (ICP). Corticosteroids are not recommended, because randomized trials in adults with IPH have failed to show efficacy $[45,46]$. Additionally, hyperglycemia which may result from corticosteroid use has been shown to be detrimental $[47,48]$.

\section{Potential treatments for IPH}

Treatment of children with IPH has primarily been guided by extrapolation from the adult literature. Treatment of brain AVM depends on the size, venous drainage pattern (superficial or deep) and location (eloquent or non-eloquent brain) [49]. In general, small, superficial AVMs in non-eloquent brain locations are microsurgically resected while AVMs that do not fall into this group require careful selection of therapy. Embolization (an interventional radiology procedure) may facilitate microsurgery or radiosurgery by reducing the size of the AVM, or rarely may obliterate the AVM entirely. Radiosurgery typically results in involution of an AVM over 3 to 5 years to achieve angiographic obliteration [50]. During this period of involution hemorrhage risk is reduced by approximately half [51]. Radiosurgery requires radiation exposure and is not preferred for young children as it may have detrimental cognitive effects [52]. In a recent series of 38 children treated with radiosurgery for AVM with a median follow up of 42 months, $68 \%$ had excellent outcomes, as defined by complete obliteration of the AVM with no new deficit [53]. Large AVMs with deep venous drainage in eloquent brain regions may not be amenable to therapy [49]. Adding to the calculus regarding treatment is the fact that in the New York Islands AVM study, recurrent AVM hemorrhage did not alter clinical outcome and had a low mortality $[54,55]$.

Optimum treatment for IPH and IVH remains elusive even in adults. Stereotactic and endoscopic surgical evacuation of the intracerebral hematoma [56,57] or hemostatic agents [58] are being investigated. Intraparenchymal and intraventricular ultra low-dose thrombolytics to promote lysis of the hematoma are currently in phase II and III randomized 
clinical trials $[59,60]$. These interventions are all of potential therapeutic benefit in adults and, by extension, in children.

Surgical hematoma evacuation for parenchyma hemorrhage deserves special mention, since management practices may differ between adults and children. The STICH trial is a landmark, recently completed trial of 1033 adult patients with spontaneous supratentorial IPH that showed that emergent surgical evacuation of hematoma within 72 hours of onset of bleeding does not improve outcome beyond best medical management [61]. However, the trial depended on clinical equipoise, i.e. patients who were felt most likely to benefit from surgery by the local investigator were not enrolled in the trial. Young patients with lobar hemorrhages with clinical deterioration due to mass effect have been shown to benefit from early surgery in a small retrospective series [62], so such patients are unlikely to have been enrolled in the STICH trial. Children may require more urgent intervention to reduce ICP and prevent brain herniation, because they do not have cerebral atrophy that would allow for expansion of the hematoma. Further, in adult series, patients with cerebellar hemorrhage $>3 \mathrm{~cm}$ in diameter benefit from early evacuation of the hematoma, likely because the location of the hemorrhage often leads to tonsillar herniation, hydrocephalus, or brainstem compression [14,63].

One of the most promising therapies with specific application to children, because it is minimally invasive and is FDA-approved for use in a subset of children already, is recombinant Factor VIIa. This drug promotes hemostasis and is licensed for use in adults and children with hemophilia who have systemic bleeding and who are resistant to factor VIII therapy. Factor VIIa is currently in phase III clinical trials in adult ICH [64]; since up to $38 \%$ of patients with IPH will have early expansion of their hemorrhage [58], stabilization of the intracerebral hematoma may reduce hemorrhage volume and improve clinical outcome. The major limitations of Factor VIIa include the potential for thromboembolic complications [65] and the need for rapid administration, ideally within 4 hours of IPH onset [58]. There are very few data on time to presentation in children with IPH. Gabis et al. [66] collected data on time from symptom onset to presentation in seven children with IPH (primary SAH and IVH were excluded) and 17 children with ischemic stroke. While the average time from first clinical symptom to first physical examination was 14.3 hours in children with IPH, four of seven patients were seen in less than 3 hours (a higher percentage than those with ischemic stroke). Though more data are needed, some children with IPH may be candidates for time-sensitive therapies.

\section{Neurologic outcome and HS recurrence}

Neurologic outcome after childhood arterial ischemic stroke has been reported by several groups [67-69]. Outcome after HS, however, has not been well studied in children. Most studies that have reported outcomes have simply reported mortality, or based on chart review, have reported neurologic outcome qualitatively (e.g. "normal, good, or poor" outcome; Table 1). Little attention has been paid to cognitive outcomes, with the exception of one retrospective cohort study of 56 Dutch children $<16$ years of age at onset of HS who received care at a single medical center between 1978 and 1998 [5]. Long-term follow up (mean 10.3 years) was available on all 36 surviving patients; 10-year survival after HS was 64\%. Mean Full Scale Intelligence Quotient (IQ) of the 31 subjects who reported for cognitive testing was not below average (IQ 106, SD 20, $\mathrm{n}=28$ ) or left-shifted. However, 15 of 31 patients (48\%) had signs of cognitive deficits when their performance was compared to their pre-morbid academic abilities or to those of their parents. And, seven patients had moderate to severe cognitive deficits. In this small sample, no relationship was found between cognitive deficits and HS location, age at the onset, time since HS, or modified Rankin score.

Factors that predict poor neurologic outcome after childhood HS are of interest. Young age at the time of HS may be a poor prognostic factor. Data in young children are sparse; however, 
in a series of 11 full-term neonates with IPH only 4 of $11(36 \%)$ had a normal neurologic examination at a mean follow up of 4.5 years [17]. Children with hemophilia who suffer a brain hemorrhage often do so at the time of birth or during the first two years of life [28,29]; neonates have the worst neurologic outcomes [28]. One study of 34 children specifically addressed features that predict poor neurologic outcome; Meyer-Heim et al. [16] found that infratentorial location, Glasgow Coma Score (GCS) $\geq 7$ at admission, aneurysm, age $<3$ years at the time of HS, and underlying hematological disorder all were predictors of more severe outcome. In the adult literature, volume of IPH and GCS $<9$ at the time of presentation are strong predictors of 30-day mortality [70]. Additional poor prognostic factors in adults have included older age, infratentorial origin of hemorrhage, and the presence of intraventricular hemorrhage [71].

Larger studies are needed to determine if these associations hold in children.

The mortality rate from HS in US children as studied via death certificate data from the National Center for Health Statistics fell dramatically from 1979 to 1998 [72]. Mortality from SAH decreased by $79 \%$, and mortality from IPH declined 58\%. Improvements in pediatric critical care and neurosurgical techniques may account from some of this reduction in mortality [7, 72]. Pooled data from multiple, somewhat heterogeneous studies suggest an average mortality of $25 \%$ in children with HS [6], although individual study estimates range from 7\% [73] to $54 \%[22]$.

Recurrence risk in childhood HS depends on underlying etiology. Children with underlying hematologic disorders and vascular malformations have the highest risk of recurrence [21, 74]. Data from pooled studies suggest that recurrence risk after HS is approximately 10\% [6], but length of follow-up was highly variable. A recent study followed 251 children with brain AVMs for a total of 996 person-years and found that the risk of subsequent IPH (after AVM detection) was $2 \%$ per year without treatment [75].

\section{Discussion}

This review attempts to synthesize existing literature on HS in childhood. Studies published in English that included patients with HS are listed in Table 1 with information about study design, number of participants, mortality and neurologic outcome. Table 2 shows the etiologies reported in these studies. This is clearly a heterogeneous group of studies with different methodologies, study populations, and inclusion criteria. The tables serve best as reminder that we know very little about HS in children and that the extant data have limitations. Much of the information on etiology of HS was gathered prior to the availability of MRI; subtle findings such as cavernoma may have been missed by CT and CCA. Likewise, MRI is clearly the best study to identify a hemorrhagic brain tumor. A combination of imaging modalities is often required. The evaluation of children with HS varies widely, so the percentage of patients with HS of unknown etiology (Table 1) may be a function of the thoroughness of the diagnostic evaluation. And, since the majority of these HS studies were conducted at tertiary children's medical centers, there is an inherent selection bias. Patients with HS who died prior to reaching a tertiary children's medical center were excluded from most studies, so mortality is likely to be underestimated and good outcomes to be overestimated. Only one study included detailed cognitive testing in the assessment of outcome [5]. All other studies assessed outcome via record review with variable duration of follow-up.

\section{Conclusion}

While research in arterial ischemic stroke and cerebral venous sinus thrombosis is expanding, HS in children remains largely unstudied. Perhaps this should not be surprising; as recently as 1999, the American Heart Association Stroke Council formed a task force to recommend areas of "desperately needed" research in adult IPH [14]. IPH remains the only stroke subtype in 
adults without a clearly defined treatment, though many potentially effective treatments are on the horizon $[76,77]$. There is a paucity of literature to guide physicians who care for children with HS.

A few themes regarding childhood HS have emerged from this review. HS has a higher mortality than arterial ischemic stroke in children $[9,21,78]$. No studies specifically address the proper evaluation of hemorrhagic stroke in children; however, data from pediatric and adult case series suggest that conventional cerebral angiography should be strongly considered $[15,79]$, particularly if non-invasive imaging techniques are unrevealing. Neurologic outcome in children after hemorrhagic stroke has not been well studied. Based on a single study, many children who survive the initial acute period of illness have IQs in the normal range, though they appear to be below their pre-morbid level of function [5].

Additional work is needed in hemorrhagic, as well as arterial ischemic stroke in childhood. Randomized controlled trials of intervention will be essential. In HS, particularly important data that are needed to plan randomized controlled trials include: recent population-based data on incidence and etiology of childhood HS; information on time to presentation that may affect therapeutic options; detailed information on neurologic outcome and predictors of outcome; and phase I and II treatment trials that include children.

\section{Acknowledgements}

The authors thank Rebecca Gottesman M.D. for her thoughtful review and helpful comments regarding this manuscript. This work was supported by NIH-NCRR K12 RR017627 (LJ).

\section{References}

1. Lynch JK, Hirtz DG, DeVeber G, Nelson KB. Report of the National Institute of Neurological Disorders and Stroke workshop on perinatal and childhood stroke. Pediatrics 2002;109:116-23. [PubMed: 11773550]

2. National Center for Health Statistics. Deaths, percentage of total deaths, and death rates for the 10 leading causes of death in selected age groups, by race and sex: United States, 2002. [Accessed June 16, 2006]. Updated November 2005; Available at: www.cdc.gov/nchs/data/nvsr/nvsr53/nvsr53_17.pdf

3. Heideman, RL.; Packer, RJ.; Albright, LA.; Freeman, CR.; Rorke, LB. Tumors of the central nervous system. In: Pizzo, PA.; Paplack, DG., editors. Principles and Practice of Pediatric Oncology. 3. Philadelphia, PA: Lippincott; 1997. p. 633-97.

4. Fullerton HJ, Wu YW, Zhao S, Johnston SC. Risk of stroke in children: ethnic and gender disparities. Neurology 2003;61:189-94. [PubMed: 12874397]

5. Blom I, De Schryver EL, Kappelle LJ, Rinkel GJ, Jennekens-Schinkel A, Peters AC. Prognosis of haemorrhagic stroke in childhood: a long-term follow-up study. Dev MedChild Neurol 2003;45:23339.

6. Lynch JK, Han CJ. Pediatric stroke: what do we know and what do we need to know? SeminNeurol 2005;25:410-23.

7. Huang J, McGirt MJ, Gailloud P, Tamargo RJ. Intracranial aneurysms in the pediatric population: case series and literature review. SurgNeurol 2005;63:424-32.

8. Sanai N, Quinones-Hinojosa A, Gupta NM, Perry V, Sun PP, Wilson CB, et al. Pediatric intracranial aneurysms: durability of treatment following microsurgical and endovascular management. J Neurosurg 2006;104(2 Suppl):82-9. [PubMed: 16506494]

9. Broderick J, Talbot GT, Prenger E, Leach A, Brott T. Stroke in children within a major metropolitan area: the surprising importance of intracerebral hemorrhage. J Child Neurol 1993;8:250-5. [PubMed: 8409267]

10. Pediatric Stroke Working Group. Stroke in childhood: clinical guidelines for diagnosis, management and rehabilitation. 2004 [Accessed July 1, 2006.]. Available at:

http://www.rcplondon.ac.uk/pubs/books/childstroke/childstroke_guidelines.pdf 
11. Monagle P, Chan A, Massicotte P, Chalmers E, Michelson AD. Antithrombotic therapy in children: the Seventh ACCP Conference on Antithrombotic and Thrombolytic Therapy. Chest 2004;126(3 Suppl):645S-87S. [PubMed: 15383489]

12. Giroud M, Lemesle M, Madinier G, Manceau E, Osseby GV, Dumas R. Stroke in children under 16 years of age. Clinical and etiological difference with adults. Acta NeurolScand 1997;96:401-6.

13. Foulkes MA, Wolf PA, Price TR, Mohr JP, Hier DB. The Stroke Data Bank: design, methods, and baseline characteristics. Stroke 1988;19:547-54. [PubMed: 3363586]

14. Broderick JP, Adams HP Jr, Barsan W, Feinberg W, Feldmann E, Grotta J, et al. Guidelines for the management of spontaneous intracerebral hemorrhage: A statement for healthcare professionals from a special writing group of the Stroke Council, American Heart Association. Stroke 1999;30:905-15. [PubMed: 10187901]

15. Al-Jarallah A, Al-Rifai MT, Riela AR, Roach ES. Nontraumatic brain hemorrhage in children: etiology and presentation. J Child Neurol 2000;15:284-9. [PubMed: 10830193]

16. Meyer-Heim AD, Boltshauser E. Spontaneous intracranial haemorrhage in children: aetiology, presentation and outcome. Brain Dev 2003;25:416-21. [PubMed: 12907276]

17. Sandberg DI, Lamberti-Pasculli M, Drake JM, Humphreys RP, Rutka JT. Spontaneous intraparenchymal hemorrhage in full-term neonates. Neurosurgery 2001;48:1042-8. [PubMed: 11334270]

18. Duhem R, Vinchon M, Leblond P, Soto-Ares G, Dhellemmes P. Cavernous malformations after cerebral irradiation during childhood: report of nine cases. Childs Nerv Syst 2005;21:922-5. [PubMed: 15662523]

19. Chung B, Wong V. Pediatric stroke among Hong Kong Chinese subjects. Pediatrics 2004;114:e20612. [PubMed: 15286258]

20. Weber AL. History of head and neck radiology: past, present, and future. Radiology 2001;218:1524. [PubMed: 11152774]

21. Lanthier S, Carmant L, David M, Larbrisseau A, de Veber G. Stroke in children: the coexistence of multiple risk factors predicts poor outcome. Neurology 2000;54:371-78. [PubMed: 10668698]

22. Livingston JH, Brown JK. Intracerebral haemorrhage after the neonatal period. Arch Dis Child 1986;61:538-44. [PubMed: 3729521]

23. Jarjour IT, Ahdab-Barmada M. Cerebrovascular lesions in infants and children dying after extracorporeal membrane oxygenation. Pediatr Neurol 1994;10:13-9. [PubMed: 8198668]

24. Strouse JJ, Hubert ML, Debaun MR, Jordan LC, Casella JF. Primary hemorrhagic stroke in children with sickle cell disease is associated with recent transfusion and use of corticosteroids. Pediatrics. 2006in press

25. Kyrnetskiy EE, Kun LE, Boop FA, Sanford RA, Khan RB. Types, causes, and outcome of intracranial hemorrhage in children with cancer. J Neurosurg 2005;102(Suppl):31-5. [PubMed: 16206731]

26. Lilleyman JS. Intracranial haemorrhage in idiopathic thrombocytopenic purpura. Paediatric Haematology Forum of the British Society for Haematology Arch Dis Child 1994;71:251-3.

27. Butros LJ, Bussel JB. Intracranial hemorrhage in immune thrombocytopenic purpura: a retrospective analysis. J Pediatr Hematol Oncol 2003;25:660-4. [PubMed: 12902925]

28. Klinge J, Auberger K, Auerswald G, Brackmann HH, Mauz-Korholz C, Kreuz W. Prevalence and outcome of intracranial haemorrhage in haemophiliacs--a survey of the paediatric group of the German Society of Thrombosis and Haemostasis (GTH). Eur J Pediatr 1999;158(Suppl 3):S162-5. [PubMed: 10650860]

29. Revel-Vilk S, Golomb MR, Achonu C, Stain AM, Armstrong D, Barnes MA, et al. Effect of intracranial bleeds on the health and quality of life of boys with hemophilia. J Pediatr 2004;144:4905. [PubMed: 15069398]

30. Yoffe G, Buchanan GR. Intracranial hemorrhage in newborn and young infants with hemophilia. J Pediatr 1988;113:333-6. [PubMed: 3397796]

31. Martinowitz U, Heim M, Tadmor R, Eldor A, Rider I, Findler G, et al. Intracranial hemorrhage in patients with hemophilia. Neurosurgery 1986;18:538-41. [PubMed: 3086767]

32. Earley CJ, Kittner SJ, Feeser BR, Gardner J, Epstein A, Wozniak MA, et al. Stroke in children and sickle-cell disease: Baltimore-Washington Cooperative Young Stroke Study. Neurology 1998;51:169-76. [PubMed: 9674798] 
33. Ohene-Frempong K, Weiner SJ, Sleeper LA, Miller ST, Embury S, Moohr JW, et al. Cerebrovascular accidents in sickle cell disease: rates and risk factors. Blood 1998;91:288-94. [PubMed: 9414296]

34. Diggs LW, Brookoff D. Multiple cerebral aneurysms in patients with sickle cell disease. South Med J 1993;86:377-9. [PubMed: 8465211]

35. Dobson SR, Holden KR, Nietert PJ, Cure JK, Laver JH, Disco D, et al. Moyamoya syndrome in childhood sickle cell disease: a predictive factor for recurrent cerebrovascular events. Blood 2002;99:3144-50. [PubMed: 11964276]

36. Royal JE, Seeler RA. Hypertension, convulsions, and cerebral haemorrhage in sickle-cell anaemia patients after blood-transfusions. Lancet 1978;2:1207. [PubMed: 82175]

37. Henderson JN, Noetzel MJ, McKinstry RC, White DA, Armstrong M, DeBaun MR. Reversible posterior leukoencephalopathy syndrome and silent cerebral infarcts are associated with severe acute chest syndrome in children with sickle cell disease. Blood 2003;101:415-9. [PubMed: 12393443]

38. Atweh GF, DeSimone J, Saunthararajah Y, Fathallah H, Weinberg RS, Nagel RL, et al. Hemoglobinopathies. Hematology Am Soc Hematol Educ Program 2003:14-39. [PubMed: 14633775]

39. Kidwell CS, Chalela JA, Saver JL, Starkman S, Hill MD, Demchuk AM, et al. Comparison of MRI and CT for detection of acute intracerebral hemorrhage. JAMA 2004;292:1823-30. [PubMed: 15494579]

40. Liu AC, Segaren N, Cox TS, Hayward RD, Chong WK, Ganesan V, et al. Is there a role for magnetic resonance imaging in the evaluation of non-traumatic intraparenchymal haemorrhage in children? Pediatr Radiol. 2006in press

41. Lin CL, Loh JK, Kwan AL, Howng SL. Spontaneous intracerebral hemorrhage in children. Kaohsiung J Med Sci 1999;15:146-51. [PubMed: 10224838]

42. Burger IM, Murphy KJ, Jordan LC, Tamargo RJ, Gailloud P. Safety of cerebral digital subtraction angiography (DSA) in children. Complication rate analysis in 241 consecutive diagnostic angiograms. Stroke 2006;37:2535-9. [PubMed: 16946163]

43. Schwarz S, Hafner K, Aschoff A, Schwab S. Incidence and prognostic significance of fever following intracerebral hemorrhage. Neurology 2000;54:354-61. [PubMed: 10668696]

44. Gebel JM Jr, Jauch EC, Brott TG, Khoury J, Sauerbeck L, Salisbury S, et al. Natural history of perihematomal edema in patients with hyperacute spontaneous intracerebral hemorrhage. Stroke 2002;33:2631-5. [PubMed: 12411653]

45. Poungvarin N, Bhoopat W, Viriyavejakul A, Rodprasert P, Buranasiri P, Sukondhabhant S, et al. Effects of dexamethasone in primary supratentorial intracerebral hemorrhage. N Engl J Med 1987;316:1229-33. [PubMed: 3574383]

46. Tellez H, Bauer RB. Dexamethasone as treatment in cerebrovascular disease. 1. A controlled study in intracerebral hemorrhage. Stroke 1973;4:541-6. [PubMed: 4579368]

47. Passero S, Ciacci G, Ulivelli M. The influence of diabetes and hyperglycemia on clinical course after intracerebral hemorrhage. Neurology 2003;61:1351-6. [PubMed: 14638954]

48. Weir CJ, Murray GD, Dyker AG, Lees KR. Is hyperglycaemia an independent predictor of poor outcome after acute stroke? Results of a long-term follow up study. BMJ 1997;314:1303-6. [PubMed: 9158464]

49. Clatterbuck RE, Hsu FP, Spetzler RF. Supratentorial arteriovenous malformations. Neurosurgery 2005;57(1 Suppl):164-7. [PubMed: 15987584]

50. Shin M, Kawamoto S, Kurita H, Tago M, Sasaki T, Morita A, et al. Retrospective analysis of a 10year experience of stereotactic radio surgery for arteriovenous malformations in children and adolescents. J Neurosurg 2002;97:779-84. [PubMed: 12405363]

51. Maruyama K, Kawahara N, Shin M, Tago M, Kishimoto J, Kurita H, et al. The risk of hemorrhage after radiosurgery for cerebral arteriovenous malformations. N Engl J Med 2005;352:146-53. [PubMed: 15647577]

52. Levy EI, Niranjan A, Thompson TP, Scarrow AM, Kondziolka D, Flickinger JC, et al. Radiosurgery for childhood intracranial arteriovenous malformations. Neurosurgery 2000;47:834-41. [PubMed: 11014422]

53. Cohen-Gadol AA, Pollock BE. Radiosurgery for arteriovenous malformations in children. J Neurosurg 2006;104(6 Suppl):388-91. [PubMed: 16776373] 
54. Choi JH, Mast H, Sciacca RR, Hartmann A, Khaw AV, Mohr JP, et al. Clinical outcome after first and recurrent hemorrhage in patients with untreated brain arteriovenous malformation. Stroke 2006;37:1243-47. [PubMed: 16614321]

55. Stapf C, Mast H, Sciacca RR, Berenstein A, Nelson PK, Gobin YP, et al. The New York Islands AVM Study: design, study progress, and initial results. Stroke 2003;34:e29-33. [PubMed: 12690217]

56. Vespa P, McArthur D, Miller C, O’Phelan K, Frazee J, Kidwell C, et al. Frameless stereotactic aspiration and thrombolysis of deep intracerebral hemorrhage is associated with reduction of hemorrhage volume and neurological improvement. Neurocrit Care 2005;2:274-81. [PubMed: 16159075]

57. Cho DY, Chen CC, Chang CS, Lee WY, Tso M. Endoscopic surgery for spontaneous basal ganglia hemorrhage: comparing endoscopic surgery, stereotactic aspiration, and craniotomy in noncomatose patients. Surg Neurol 2006;65:547-55. [PubMed: 16720167]

58. Mayer SA, Brun NC, Begtrup K, Broderick J, Davis S, Diringer MN, et al. Recombinant activated factor VII for acute intracerebral hemorrhage. N Engl J Med 2005;352:777-85. [PubMed: 15728810]

59. Barrett RJ, Hussain R, Coplin WM, Berry S, Keyl PM, Hanley DF, et al. Frameless stereotactic aspiration and thrombolysis of spontaneous intracerebral hemorrhage. Neurocrit Care 2005;3:23745. [PubMed: 16377836]

60. Naff NJ, Hanley DF, Keyl PM, Tuhrim S, Kraut M, Bederson J, et al. Intraventricular thrombolysis speeds blood clot resolution: results of a pilot, prospective, randomized, double-blind, controlled trial. Neurosurgery 2004;54:577-83. [PubMed: 15028130]

61. Mendelow AD, Gregson BA, Fernandes HM, Murray GD, Teasdale GM, Hope DT, et al. Early surgery versus initial conservative treatment in patients with spontaneous supratentorial intracerebral haematomas in the International Surgical Trial in Intracerebral Haemorrhage (STICH): a randomised trial. Lancet 2005;365:387-97. [PubMed: 15680453]

62. Rabinstein AA, Atkinson JL, Wijdicks EF. Emergency craniotomy in patients worsening due to expanded cerebral hematoma: to what purpose? Neurology 2002;58:1367-72. [PubMed: 12011282]

63. Mathew P, Teasdale G, Bannan A, Oluoch-Olunya D. Neurosurgical management of cerebellar haematoma and infarct. J Neurol Neurosurg Psychiatry 1995;59:287-92. [PubMed: 7673958]

64. Mayer SA, Rincon F. Treatment of intracerebral haemorrhage. Lancet Neurol 2005;4:662-72. [PubMed: 16168935]

65. O'Connell KA, Wood JJ, Wise RP, Lozier JN, Braun MM. Thromboembolic adverse events after use of recombinant human coagulation factor VIIa. JAMA 2006;295:293-8. [PubMed: 16418464]

66. Gabis LV, Yangala R, Lenn NJ. Time lag to diagnosis of stroke in children. Pediatrics 2002;110:9248. [PubMed: 12415031]

67. Ganesan V, Hogan A, Shack N, Gordon A, Isaacs E, Kirkham FJ. Outcome after ischaemic stroke in childhood. Dev Med Child Neurol 2000;42:455-61. [PubMed: 10972417]

68. De Schryver EL, Kappelle LJ, Jennekens-Schinkel A, Boudewyn Peters AC. Prognosis of ischemic stroke in childhood: a long-term follow-up study. Dev Med Child Neurol 2000;42:313-8. [PubMed: 10855651]

69. Hetherington R, Tuff L, Anderson P, Miles B, deVeber G. Short-term intellectual outcome after arterial ischemic stroke and sinovenous thrombosis in childhood and infancy. J Child Neurol 2005;20:553-9. [PubMed: 16159518]

70. Broderick JP, Brott TG, Duldner JE, Tomsick T, Huster G. Volume of intracerebral hemorrhage. A powerful and easy-to-use predictor of 30-day mortality. Stroke 1993;24:987-93. [PubMed: 8322400]

71. Hemphill JC 3rd, Bonovich DC, Besmertis L, Manley GT, Johnston SC. The ICH score: a simple, reliable grading scale for intracerebral hemorrhage. Stroke 2001;32:891-7. [PubMed: 11283388]

72. Fullerton HJ, Chetkovich DM, Wu YW, Smith WS, Johnston SC. Deaths from stroke in US children, 1979 to 1998. Neurology 2002;59:34-9. [PubMed: 12105304]

73. Visudhiphan P, Chiemchanya S, Wattanasirichaigoon D. Strokes in Thai children: etiology and outcome. Southeast Asian J Trop Med Public Health 1996;27:801-5. [PubMed: 9253888]

74. Nelson MD Jr, Maeder MA, Usner D, Mitchell WG, Fenstermacher MJ, Wilson DA, et al. Prevalence and incidence of intracranial haemorrhage in a population of children with haemophilia. The Hemophilia Growth and Development Study Haemophilia 1999;5:306-12. 
75. Fullerton HJ, Achrol AS, Johnston SC, McCulloch CE, Higashida RT, Lawton MT, et al. Long-term hemorrhage risk in children versus adults with brain arteriovenous malformations. Stroke 2005;36:2099-104. [PubMed: 16141419]

76. Hanley DF, Hacke W. Critical care and emergency medicine neurology. Stroke 2004;35:365-6. [PubMed: 14757881]

77. Rincon F, Mayer SA. Novel therapies for intracerebral hemorrhage. Curr Opin Crit Care 2004;10:94100. [PubMed: 15075717]

78. Schoenberg BS, Mellinger JF, Schoenberg DG. Cerebrovascular disease in infants and children: a study of incidence, clinical features, and survival. Neurology 1978;28:763-8. [PubMed: 567292]

79. Zhu XL, Chan MS, Poon WS. Spontaneous intracranial hemorrhage: which patients need diagnostic cerebral angiography? A prospective study of 206 cases and review of the literature. Stroke 1997;28:1406-9. [PubMed: 9227692]

80. Eeg-Olofsson Eeg-Olofsson O, Ringheim Y. Stroke in children. Clinical characteristics and prognosis. Acta Paediatr Scand 1983;72:391-5. [PubMed: 6880725]

81. Beran-Koehn, Brown RD, Mellinger JF, Christianson TJ, O'Fallon WM. Cerebrovascular disease in children: incidence, etiology and outcome. Neurology 1999;52(Suppl 2):A43-4.

82. Zahuranec DB, Brown DL, Lisabeth LD, Morgenstern LB. Is it time for a large, collaborative study of pediatric stroke? Stroke 2005;36:1825-9. [PubMed: 16100029] 


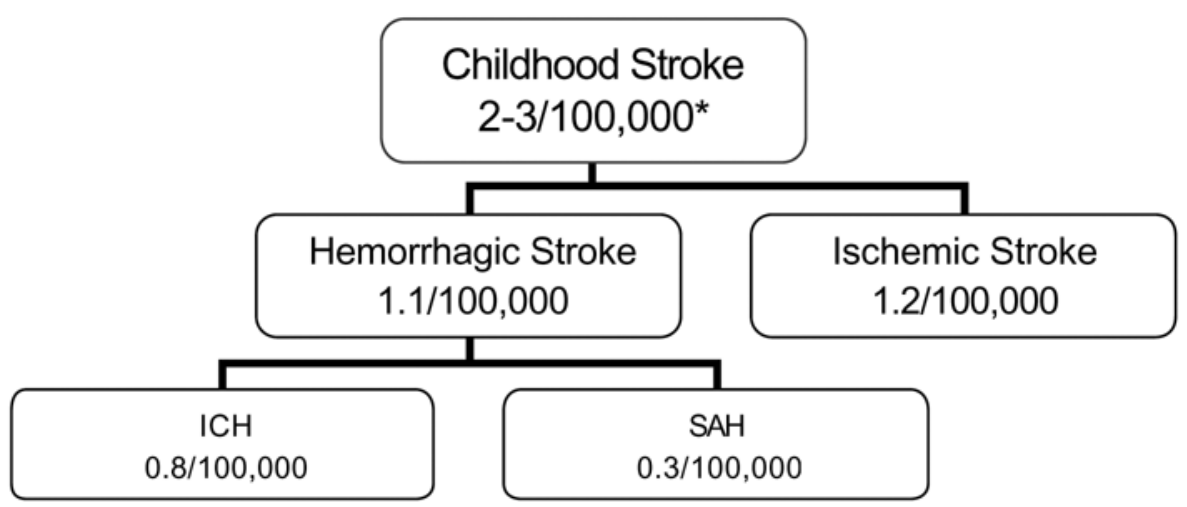

Figure 1.

Childhood Stroke Incidence by Subtype

* per 100,000 children per year

Incidence numbers from Fullerton el al.[4]. 
Jordan M.D. and Hillis M.D.

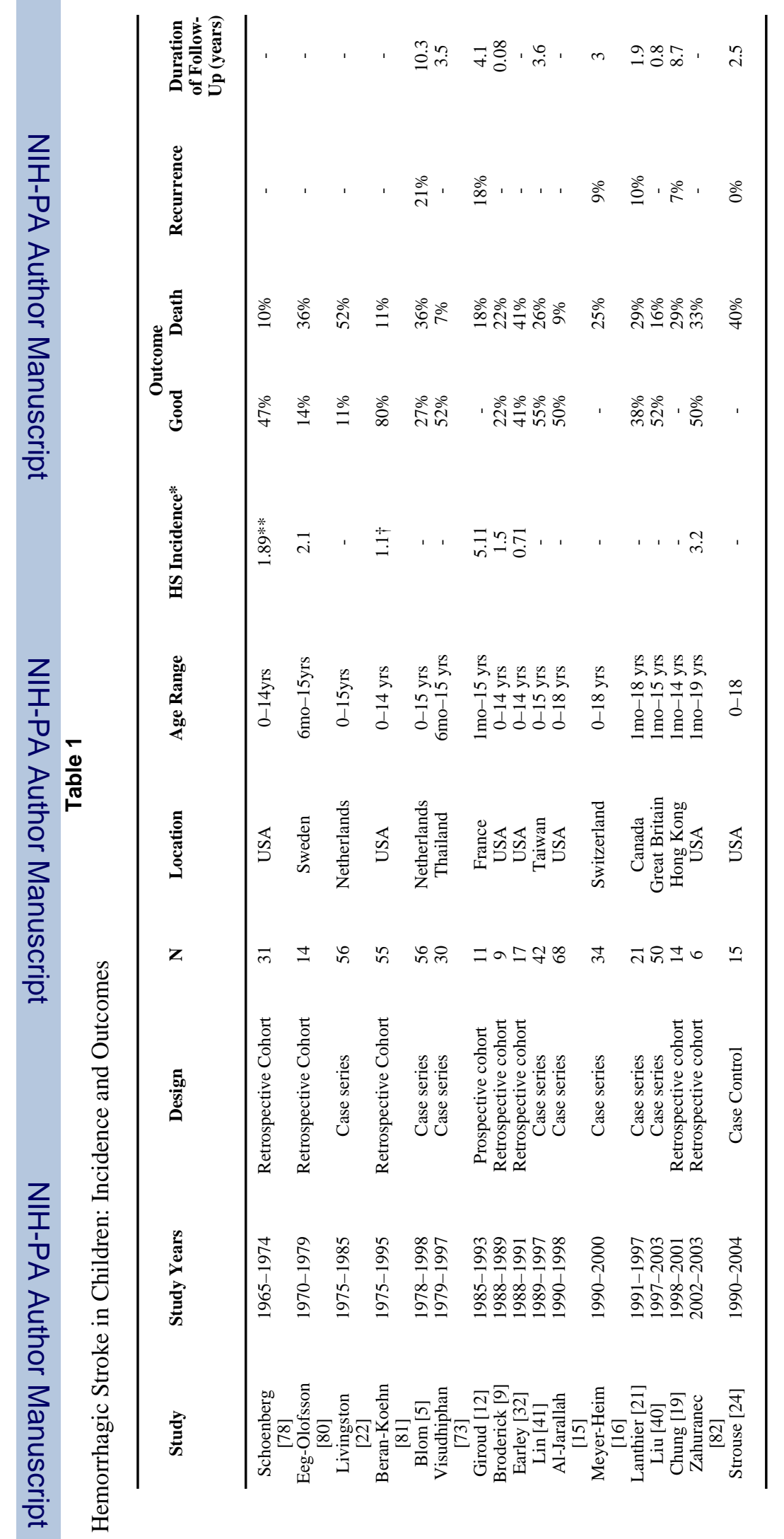


Jordan M.D. and Hillis M.D.

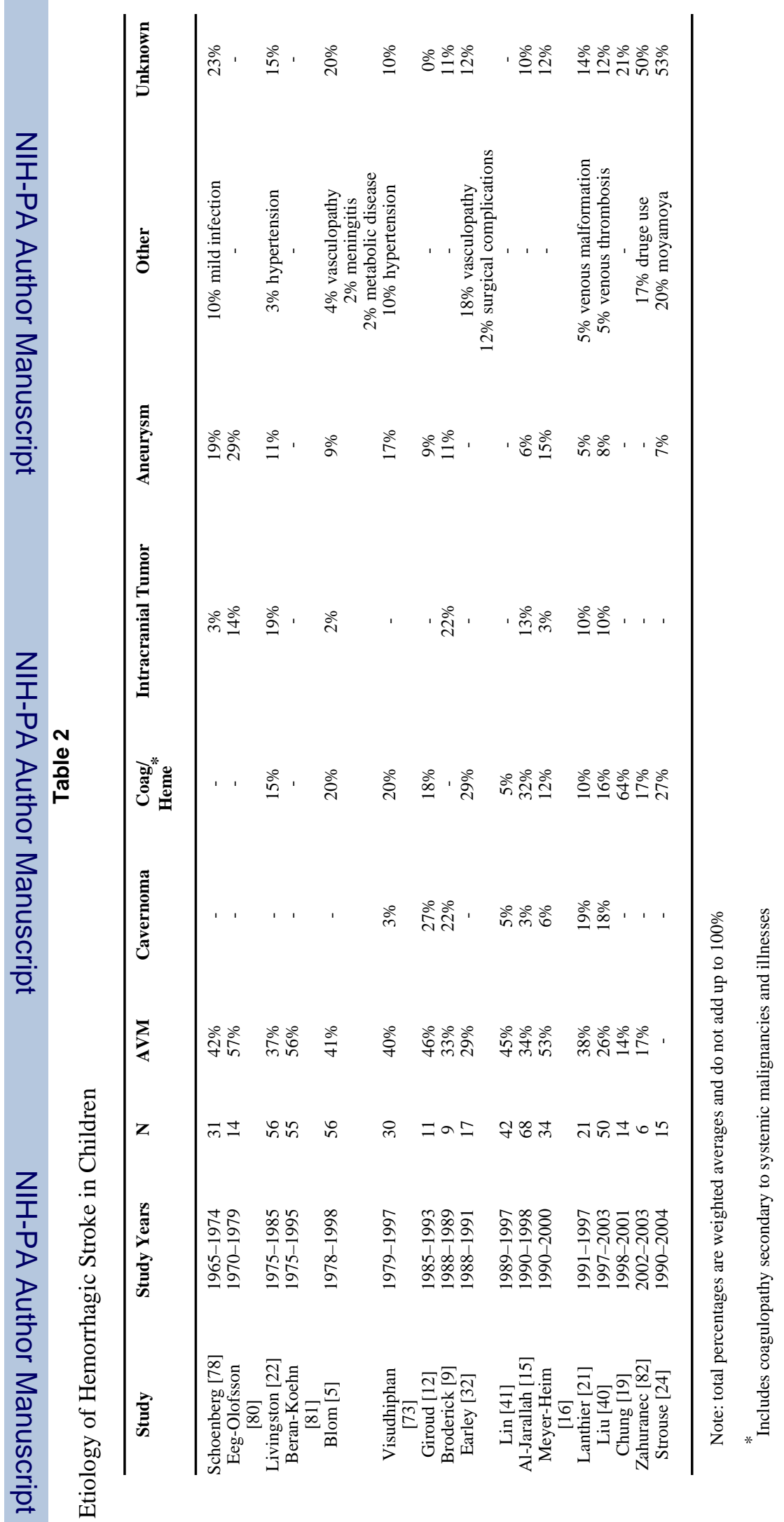

